\title{
DIGITALCOMMONS
}

$5-1-2017$

\section{Book Review: Multivariate Statistical Methods, A Primer}

C. R. Rao

University of Buffalo, crr1@psu.edu

Follow this and additional works at: http://digitalcommons.wayne.edu/jmasm

Part of the Applied Statistics Commons, Social and Behavioral Sciences Commons, and the Statistical Theory Commons

\section{Recommended Citation}

Rao, C. R. (2017). Book Review: Multivariate Statistical Methods, A Primer. Journal of Modern Applied Statistical Methods, 16(1), 776-777. doi: $10.22237 /$ jmasm/1493599260

This Book Review is brought to you for free and open access by the Open Access Journals at DigitalCommons@WayneState. It has been accepted for inclusion in Journal of Modern Applied Statistical Methods by an authorized editor of DigitalCommons@WayneState. 


\section{Book Review: Multivariate Statistical Methods, A Primer}

\section{R. Rao}

University at Buffalo

Buffalo, NY

Multivariate Statistical Methods, A Primer, $4^{\text {th }}$ Ed. Bryan F. J. Manly and Jorge A. Navarro Alberto. NY: Chapman \& Hall / CRC Press. 2016. 264 p. ISBN 10: 1498728960 / ISBN 13: 978-1498728966

The purpose of the book is to introduce multivariate statistical methods to nonmathematicians. It is assumed that readers have a working knowledge of elementary statistics, including tests of significance using normal, $t$, Chi-squared and $F$ distributions, analysis of variance and linear regression. The authors made an excellent effort by presenting multivariate data of different kinds, such as body measurements, made on two or more kinds of individuals within each group and raising questions such as how different the measurements are within groups and how different they are between different kinds of individuals. With one measurement, differences between groups is examined by comparing individual mean values and variances within groups. With $p$ measurements, $p$ mean values are needed, and $p(p-1)$ variances and covariances for comparison. Appropriate multivariate methods for this purpose have been demonstrated. In addition, there is the problem of grouping given populations by similarity of measurements which needs a measure of distance between populations based on observed data.

The authors give a good account of different methods available for these purposes. Some of the measures of similarity such as Penrose and Mahalanobis distances are mentioned for possible use. Penrose distance does not take into account correlations between measurements and may not be appropriate in all practical applications. Mahalanobis distance will be appropriate for correlated variables when the measurements are nearly normally distributed. Some discussion on the choice of distance measure to be used will be helpful to

Prof. Rao, Sc.D. (Cantab), FRS, is the Eberly Professor Emeritus of Statistics and the Director of Center for Multivariate Analysis at Penn State, and Research Professor in Biostatistics at the University at Buffalo. Email him at crrl @psu.edu. 


\section{R. RAO}

practical workers. The authors describe all available statistical methods for these purposes in terms of principal components, factor analysis, discriminant functions and canonical correlation analysis.

Multivariate analysis was developed during the 1940s. The Anthropology Department at Cambridge University, UK sent an expedition to Jebel Moya in Africa to dig ancient graves and bring the skeletons back for study. Their purpose was to analyze multiple measurements to find their relationship with skeletal material available in nearby areas. This is a multivariate problem for which no solution was available at that time.

Professor Trevor, a member of the Anthropology faculty, heard about the work of Prof. Prasanta Chandra Mahalanobis and the distance from point $P$ and distribution $D$ named after him. In July, 1946 he sent a telegram to Prof. Mahalanobis to send someone to Cambridge to analyze the skeleton measurements. At that time, I was working in the Indian Statistical Institute as a research scholar under the direction of Prof. Mahalanobis, and I had published some papers on multivariate analysis. Prof. Mahalanobis deputed me to go to Cambridge and analyze their data. I travelled to Cambridge that month, and for the following two years worked in Cambridge's Anthropology Department as a paid visiting scholar. The result was the development of the necessary tools to analyze their multivariate data, and were published in 1954 by Cambridge University Press as a book, Ancient Inhabitants of Jebel Moya, under the joint authorship of myself along with two anthropologists, Trevor and Mukherji.

Subsequently, I was asked by the President of Royal Statistical Society (RSS) to present my research work on the Jebel Moya data at a meeting of the Society, which I did in October, 1948. That material was later published in two research papers, which constitute the corpus of multivariate analysis as practiced today. One is Rao, C. R. (1948), Utilization of multiple measurements in problems of biological classification. Journal of the Royal Statistical Society, 10, 159-203. The other is Rao, C. R. (1948), Tests of significance in multivariate analysis, Biometrika, 35(1-2), 58-79. This material also provided the basis for my book Rao, C. R. (1952), Advanced Statistical Methods in Biometric Research. NY: Wiley. 